\title{
TOURISM DESTINATION COMPETITIVENESS: THE FRENCH REGIONS CASE
}

\author{
L. Botti ${ }^{\text {a, b }}$, N. Peypoch ${ }^{a^{*}}$, E. Robinot ${ }^{c}$ and B. Solonadrasana ${ }^{a}$
}

${ }^{a}$ GEREM, Institut d'Administration des Entreprises - Université de Perpignan Via Domitia, 52 avenue Paul Alduy, F - 66860 Perpignan Cedex, France.

${ }^{\mathrm{b}}$ ERFI, Institut des Sciences de l'Entreprise de Montpellier - Université Montpellier I, Espace Richter - Bât B, CS 19519, F - 34960 Montpellier Cedex 2, France.

c IREGE, Institut de Management de l’Université de Savoie, BP 80 439, F - 74 944, Annecy-le-vieux Cedex, France.

*Corresponding author, e-mail: peypoch@univ-perp.fr

\begin{abstract}
In this paper we assess and compare tourism destinations in terms of their performance. The proposed efficiency assessment procedure is based on Data Envelopment Analysis (DEA) and precisely on the Directional Distance Function. This methodology is here explained as easiest as possible and it is applied to the evaluation of the twenty-two French regions. The motivation for the analysis lies in the fact that these destinations have to (or will have to) face a decrease in their competitiveness. Then, the aim of the paper is to start a reflection on the performance of the 22 French regions; for that, its only objective is to measure the efficiency of these destinations. Indeed, knowing what the best practices are is good news for Destination Management Organizations and tourism institutions in the perspective of a benchmarking procedure. The paper still tries to explain the scores.
\end{abstract}

Keywords: France, destination competitiveness, technical efficiency

\section{Introduction}

Performance analysis is a central issue of corporate governance because in a competitive environment, a company less efficient than its competitors fails generally to maintain a sufficient market share to survive on the market. The tourism industry is not immune to this performance need. Therefore, developing tools enabling to evaluate the performance of tourism activities is of critical importance (Botti et al., 2009).

In particular, in order to provide policy makers guidelines, to correct inefficient management directions and to promote positive effects from competition, it proves fundamental to use performance indicators as regard destinations. Indeed, destination 
as a tourism product is considered to be a holistic experience. The destination experience is created not by one operation but by a minimum number of tourism facilitating services such as attraction, accommodation, transport and hospitality (figure 1). Such an experience is produced via a set of operations suggesting that the destination acts as a virtual service firm with the destination's name often as its brand.

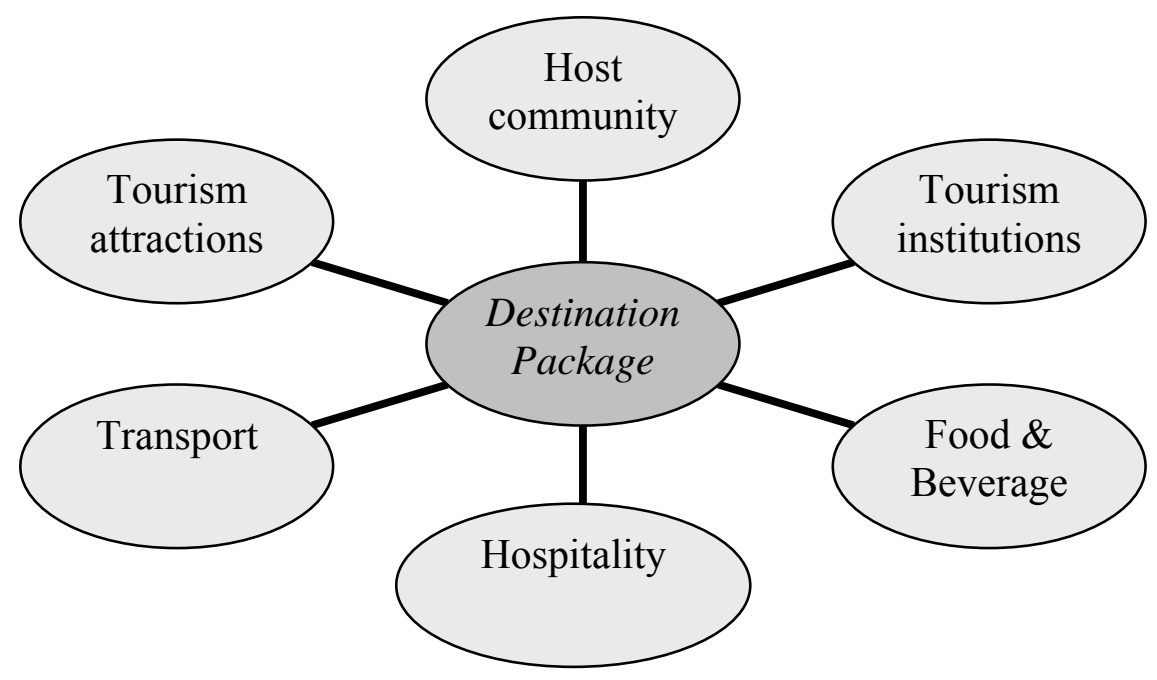

Figure 1: The destination as a tourism product

In this paper we assess and compare tourism destinations in terms of their performance. The proposed efficiency assessment procedure is based on Data Envelopment Analysis (DEA) which is a methodology for evaluating the relative efficiency when facing multiple input and output. DEA is relevant from the viewpoint of tourism destination management because it indicates not only the best destinations but also inefficient practices (which are observed practices) and efforts to provide efficiency (Barros, 2005).

This methodology is here applied to the evaluation of the twenty-two French regions. The motivation for the analysis lies in the fact that these destinations have to (or will have to) face a decrease in their competitiveness. Knowing what the best practices are is then good news for persons and organizations in charge of the tourism development of one of these regions. For each region, the analysis takes into consideration a set of indicators (inputs and outputs) which are considered relevant when valuing destination performance. To our knowledge, no current study has directly measured and compared the performance level of these destinations. Moreover, we use in our paper an innovative tool to estimate these levels. Then, our 
paper contributes to the tourism industry literature by adopting a somewhat novel approach that has never been applied to the French regions.

The article is organized as follows. The first section presents the importance of the paper that is the importance of valuing the French regions performance. The second section is about different methods for measuring performance. It justifies and presents briefly DEA and the Directional Distance Function. The third section presents data on the French regions and results of our analysis. Finally, the fourth section concludes and proposes some extensions of this paper.

\section{Importance of tourism competitiveness: the case of France}

Many authors have written about the important role played by tourism industry in the economy in general and in development in particular. During the second half of the twentieth century, tourism has become one of the main economic activities that have recorded the most important growth. As a matter of fact, in the 30-year period since the 1950s toward the end of the 1980s, total international tourist flows have grown by a factor of six, to approximately 400 millions (Chu 1998). Such a rapid expansion of tourism is linked to two main reasons (Botti et al., 2007):

(i) first. the increase of available income of wage earners in the majority of developed countries and the decrease of the working-time, thereby an increase of the spare-time;

(ii) second, the decrease of the transport charges between two destinations taking into account the considerable development of means of transport.

In 2004, France remained to be the first international destination in terms of number of arrivals. With a number of tourists reaching up to 75,1 million, France is far ahead compared to countries such as Spain (53,6 million), United States of America (46,1 million), or China (41,8 million). The account of the balance of payments shows a positive sign procuring to France 10,7 billions euros of receipts, representing therefore an increase of 7,5\% compared to the year 2003. In that case, the sector of tourism constitutes a major issue for France.

France is seen as the leading country in the area of international tourism and this can be explained by the remarkable tourism richness of the country: its 22 tourism regions receiving in 2003, 75,1 millions arrivals, that is approximately $10 \%$ of world total number of tourists. According to Peyroutet (1998), the tourists are mainly attracted first by touring the cities (31\%), then the coast, the mountains and the countryside. The most commonly chosen regions are Provence-Alpes-Côte d'Azur (103,7 million of overnight stay), Rhône-Alpes (92,1 millions of overnight stay) and Languedoc-Roussillon (76,8 millions of overnight stay). France has, presently, about 13000 edifices classified as patrimony. All of them are considered as being the tourism offer of France. Such a patrimony consists of historic and prehistoric sites, religious edifices, castles, manors, and civil buildings. 
Table 1 shows the most visited monuments in France. Besides, the country has 7500 protected sites and 140 natural reserves.

Concerning the accommodation: in 2004, France offers to its tourists a range of 27641 registered hotels from 1 to 4 luxury stars unequally allotted in its 22 regions. Furthermore, there are 8059 registered camping areas from 1 to 4 stars; 813 registered holiday villages, 217 inns, and 41957 rural as well as communal lodges and 22053 guesthouses. The supply of tourist stopping points is summarized in Table 2.

Table 1 The 5 most visited monuments in France (2004)

\begin{tabular}{|l|l|}
\hline Monuments & Visitors \\
\hline Musée du Louvre & 6600000 \\
\hline Tour Eiffel & 6200000 \\
\hline Château de Versaille & 3300000 \\
\hline Arc de Triomphe & 1200000 \\
\hline Mont Saint-Michel & 1100000 \\
\hline
\end{tabular}

Table 2 Number of beds in accommodation establishments (2004)

\begin{tabular}{|l|l|}
\hline Type of accommodation establishment & Number of beds \\
\hline Registered hotels & 1230800 \\
\hline Classified camping & 2803900 \\
\hline Holiday Villages & 607000 \\
\hline Inn & 18000 \\
\hline Lodges and guesthouses & 266000 \\
\hline
\end{tabular}

Table 3 Destinations Ranking in terms of arrivals (OMT, 2004)

\begin{tabular}{|c|c|c|c|c|c|c|c|c|}
\hline & \multirow{2}{*}{$\begin{array}{l}\text { Arrivals } \\
\text { in } 2003 \\
\text { (million) }\end{array}$} & \multirow{2}{*}{$\begin{array}{l}\text { Variation } \\
\text { from } 2002 \\
(\%)\end{array}$} & \multicolumn{6}{|c|}{ Ranking } \\
\hline & & & 1985 & 1990 & 2000 & 2002 & 2003 & 2020 \\
\hline France & 75.0 & -2.0 & 1 & 1 & 1 & 1 & 1 & 2 \\
\hline Spain & 52.3 & 0.3 & 2 & 3 & 3 & 2 & 2 & 4 \\
\hline USA & 40.4 & 3.6 & 4 & 2 & 2 & 3 & 3 & 3 \\
\hline Italia & 39.6 & 0.5 & 3 & 4 & 4 & 4 & 4 & 7 \\
\hline China & 33 & -10.3 & 13 & 12 & 5 & 5 & 5 & 1 \\
\hline UK & 24.8 & 2.6 & 6 & 7 & 6 & 6 & 6 & 6 \\
\hline Austria & 19.1 & 2.6 & 5 & 6 & 11 & 9 & 7 & $\mathrm{X}$ \\
\hline Mexico & 18.7 & -5.0 & 9 & 8 & 8 & 8 & 8 & 8 \\
\hline Germany & 18.4 & 2.4 & 8 & 9 & 11 & 10 & 9 & $\mathrm{X}$ \\
\hline Canada & 17.5 & -12.7 & 7 & 10 & 9 & 7 & 10 & $\mathrm{X}$ \\
\hline
\end{tabular}


In our times of economic crisis, the debate currently focuses in France on the tourism industry because it no longer plays the role of locomotive for growth. France, with nearly 80 million foreign visitors, was still the world's top destination in 2006, but it was only the third largest in terms of income, behind the USA and Spain. This is what is commonly called the "French paradox": France is the first tourist destination in the world in terms of number of arrivals, but it generates less revenue through the industry than other countries (Randriamboarison, 2003). Moreover, in terms of arrivals, predictions say that France will no longer be the first destination in the world.

Then, the motivation for our analysis lies in the field of tourism destination competitiveness. From the last twenty years, researchers have increased their interests in this concept. Destination' managers have been aware that besides comparative advantage and price, many other variables determine the competitiveness of the tourism destination.

A tourism destination is defined as a geographical area within the tourist enjoys various types of tourism experiences. According to Richie and Crouch (2003), it is possible to distinguish several types and levels of tourism destination: a country, a macro region, a city or a town... However, for most tourists, this experience takes places in a small geographical area, which, from a Destination Management Organization (DMO) point of view, is managerial. Ritchie and Crouch (2003) defined the competitiveness in tourism "as the element that makes a destination competitive, its ability to increase tourism expenditures, to increasingly attract visitors whiles providing them with satisfying, memorable experiences and to do so in a profitable way, while enhancing the well being of the destination residents and preserving the natural capital of the destination for future generations."

Regarding tourism literature, models to explain the competitiveness of tourism destination are numerous (Vanhove, 2005). The Porter model (1990) emphasizes the forces of firms and the related generic competitive strategies. However, it is limited. For example, it doesn't take into account macro-economic factor (economic, climatic, geographical, technological), accessibility, marketing, image, promotion (Vanhove, 2005, p. 137). The Poon model (1993) is based on the point of view that new tourism changes the rules of the game in a society and sensitize for a new strategies to ensure competitive success. But it issue is not whether to develop tourism, but rather how to develop the sector such as a way that the destination benefit. In another perspective, the West (1993) approach is based on the identification of all the macro-economic, supply, transports demand factors. It show by application of multiples regression analysis the impact of the income factor on the generating markets and the real exchange rate but it is constrained in the integration of the influence of the tourism policy. The price competitive approach (Dwyer et al., 2000) emphasizes the role of factor price by maintaining that a fall in relative cost is linked to a rise in market share. It considers as well socio-economic and demographic factors and qualitative factors 
(image, quality of tourist services...). Nevertheless, this model can be only interesting if it's possible to compare price competitive index built on the same variables which are often different according to the country (differences of accommodation, prices can vary between regions in the same country...). Using some bases of the Porter's model Crouch and Ritchie $(1999,2003)$ proposed a model which is recognized as the most comprehensive and complete one. According to the authors, destination success is determined by two different advantages. On the one hand, the comparative advantages reflect the resources endowments of the destination provided either by nature or by the overall society within which the destination resides, like physical, cultural, and historical and infrastructure attributes and human capital. On the other hand, the competitive advantages are those that have been established as a result of effective resource deployment: maintenance, growth and development, effectiveness and audit. Crouch (2006) underline that the tourism destination competitiveness will depend on how well it utilizes the available resources and the ability to add value to the available resources. In this model, quality management is considered to be strategic. Governments must take steps to establish and enforce standards to stimulate quality planning at the destination level.

In the light of the Crouch and Richie (1999) model, it is then possible to analyze the tourist destination efficiency if it were a company with inputs (the territory's physical and human resources) and outputs (arrivals, bed-nights, employment, customer satisfaction). DMO can evaluate its tourist performance. In other words, the DMO is able to extend the dispensation of inputs in an efficiency manner in order to attract a maximum share of tourist demand and to be competitive against competitors. However, according to these authors, the question of inefficiency can appear from governmental regulations, which can limit the development of the destination (for example, the French law in coastal region which limit construction in seafront) or from global forces which can influence the country (for example, a demographic trend) and from a physiographic, culture and social forces (for example, well-being of residents, environmental protections). The identification of these biases may help DMO to identify and evaluate the dysfunctions of the tourism destination efficiency and to improve these offers.

According to this line, the aim of our paper is to start a reflexion on the performance of the 22 French regions; for that, its only objective is to measure the efficiency of these destinations. Indeed, knowing what the best practices are is good news for DMOs and tourism institutions in the perspective of a benchmarking procedure. The paper still tries to explain the scores.

Next, the methodology to calculate the efficient DEA scores is presented; the scores will be exposed and discussed in the following section and a discussion about the sources of efficiency will also be held. 


\section{Production Frontier Analysis}

The DEA methodology, introduced by Charnes, Cooper, and Rhodes (1978) and generalized by Briec (1997) is a non-parametric method for the estimation of Pareto-optimal frontiers from which the efficiency of DMUs can be determined. The direct consequence of the non-parametric feature of DEA is that this method doesn't require, unlike deterministic and stochastic parametric methods, the specification of a functional form for the production technology. With $D E A$, one circumvents the problem of specifying an explicit form of the production function by making assumptions about the technology. For a comprehensive exposition of these assumptions, the reader may refer to Ray (2004) and Coelli et al. (2005). Another consequence of this non-parametric feature is that there is no sample constraint. At least has it been accepted as a convention that the size of the DMUs sample must be greater than two times the sum of inputs and outputs (Nooreha et al., 2000). At this time, a large number of articles on theoretical extensions and empirical applications of DEA have been published. Surveys of these papers can be found in Lovell and Schmidt (1998), Lovell (1993) and Tavares (2002).

Before turning to technical details, let us briefly expose how the methodology works. Indeed, while the procedure is computationally rigorous, a simple literal and graphical presentation can demonstrate its fundamental idea. The method separates the efficient DMUs from the inefficient on the basis of whether they - i.e. the input-output bundles - lie or not on the efficient frontier of the production possibility set (or simply the possibility set). This latter is composed of all the input-output vectors that are feasible with a production technology transforming a vector of inputs $x=\left(x_{1}, \ldots, x_{N}\right) \in \mathfrak{R}_{+}^{N}$ into a vector of outputs $y=\left(y_{1}, \ldots, y_{P}\right) \in \mathfrak{R}_{+}^{P}$. It can be simply written as:

$$
T=\left\{(x, y) \in \mathfrak{R}_{+}^{N+P}: x \text { can produce } y\right\}
$$

On Figure 2, we measure input $x$ along the horizontal axis and output $y$ up the vertical axis. Points A, B and C represent the input-output bundles of DMU A, B and $\mathrm{C}$ respectively. The vector $\mathrm{A}$ is efficient because we cannot decrease proportionally the input quantity used to produce the same amount of output. On the other hand, the DMU B is not efficient as it is possible (i) to reduce proportionally the input quantity used until to reach the vector $\mathrm{C}$ or (ii) expand proportionally the output quantity produced until to reach the vector $\mathrm{A}$. 


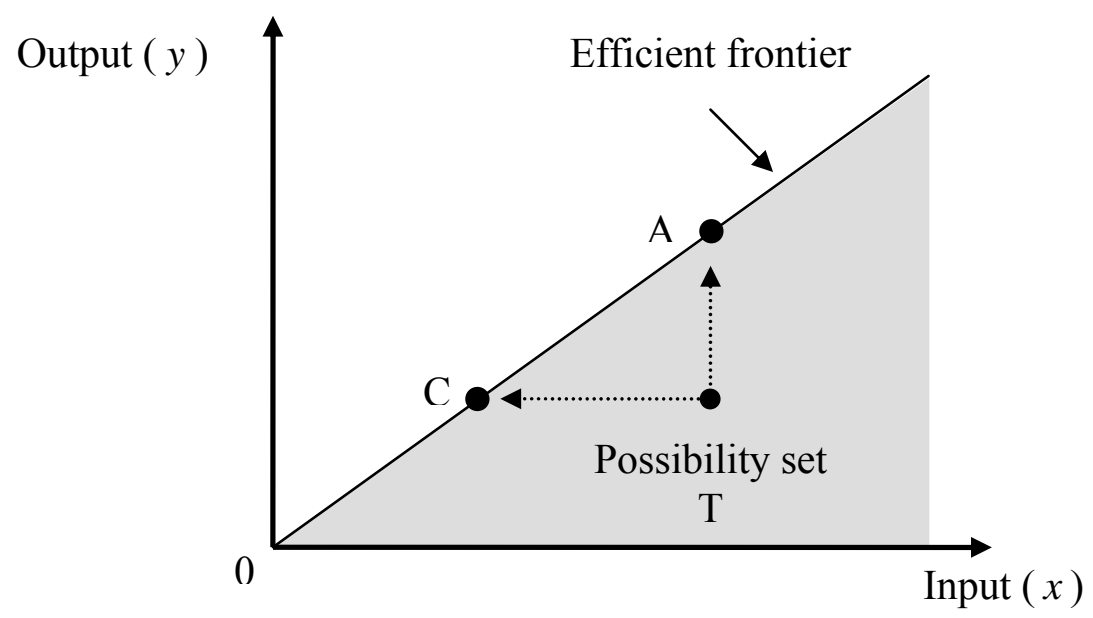

Figure 2: The possibility set $T$ and the efficient frontier

Then, when using DEA, an alternative occurs in the identification of the inefficiency as it is possible to maximize the outputs given the inputs or to minimize the use of inputs given the outputs. The latter alternative is the definition of the Debreu-Farrell measure of technical efficiency which can be written as follows (Debreu, 1951; Farrel, 1957):

$$
E_{D F}(x, y)=\min \{\theta: \theta x \in L(y)\}
$$

Where $L(y)$ is the input correspondence or the consumption set of $y$, i.e. the set of all input vectors that yield at least $y$.

With $m$ observed DMUs $\left(x^{1}, y^{1}\right),\left(x^{2}, y^{2}\right), \ldots\left(x^{m}, y^{m}\right)$, the possibility set can be defined as follows:

$$
T=\left\{(x, y): x \geq \sum_{i=1}^{m} \lambda_{i} x^{i}, y \leq \sum_{i=1}^{m} \lambda_{i} y^{i},\left(\lambda_{1}, \ldots, \lambda_{m}\right) \in \Gamma\right\}
$$

Where $\lambda$ represents the intensity of each production unit and $\Gamma$ the set which characterizes the returns to scale, i.e., the way the production process can be scaled up and down for each observation. Obtained efficiency measures are quite sensitive to alternative specifications of returns to scale. While recognizing this fact, the efficiency literature does not provide much guidance on the issue of how to evaluate the appropriateness of choices in this respect (Tulkens, 1993). In DEA, the possibility set can be based on the hypothesis of constant returns to scale (CRS), or can assume 
variable returns to scale (VRS). According to the chosen return to scale hypothesis, the set $\Gamma$ can be defined as follows:

a) Constant Returns to Scale or CRS (Charnes, Cooper, and Rhodes, 1978):

$\Gamma=\left\{\left(\lambda_{1}, \ldots \lambda_{m}\right): \lambda_{i} \geq 0, \forall i \in(1, \ldots, m)\right\}$

b) Variable Returns to Scale or VRS (Banker, Charnes and Cooper, 1984):

$$
\Gamma=\left\{\left(\lambda_{1}, \ldots \lambda_{m}\right): \sum_{i=1}^{m} \lambda_{i}=1, \forall i \in(1, \ldots, m)\right\}
$$

In Figure 3, the complete line $(\mathrm{C}, \mathrm{A})$ is the efficient frontier of the DEA CRS model. The broken line DCAB represents the frontier under variable returns-to-scale (VRS).

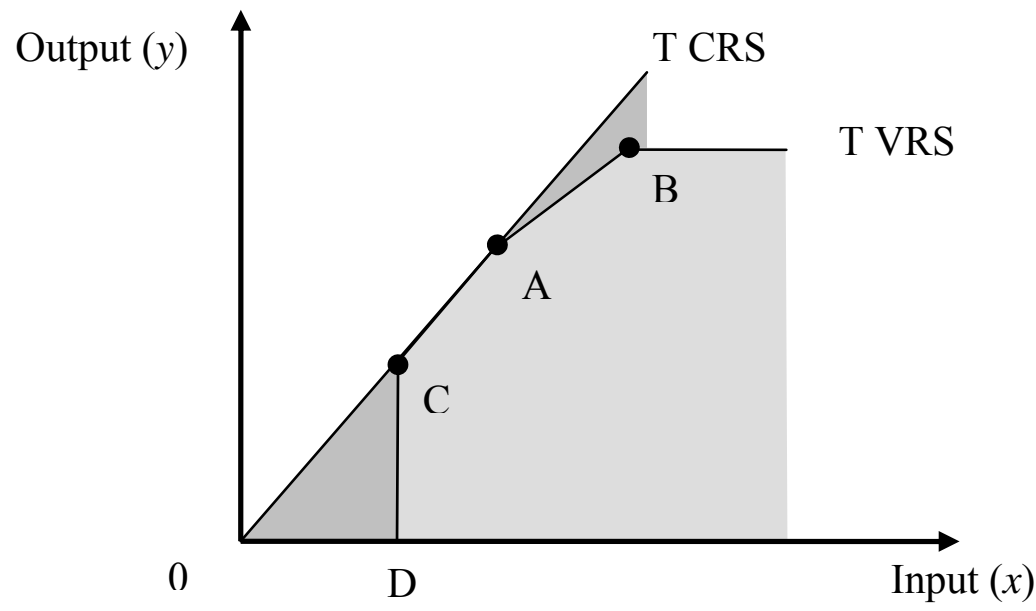

Figure 3 DEA efficient frontier under constant and various returns to scale

From the seminal article of Charnes, Cooper, and Rhodes (1978), the following linear program computes the Debreu-Farrell measure with CRS:

$E_{D F}\left(x^{j}, y^{j}\right)=\min \theta$

subject to:

$$
\begin{aligned}
& \theta x_{n}^{j} \geq \sum_{i=1}^{m} \lambda_{i} x_{n}^{i}, n=1, \ldots, N \\
& y_{p}^{j} \leq \sum_{i=1}^{m} \lambda_{i} y_{p}^{i}, p=1, \ldots, P \\
& \lambda_{i} \geq 0, i=1, \ldots, m
\end{aligned}
$$


This original DEA model has been extended to allow for varying returns to scale (i.e., first increasing and then decreasing) in Banker, Charnes and Cooper (1984). According to their article, the following linear program computes the Debreu-Farrell measure with VRS:

$$
E_{D F}\left(x^{j}, y^{j}\right)=\min \theta
$$

subject to:

$$
\begin{aligned}
& \theta x_{n}^{j} \geq \sum_{i=1}^{m} \lambda_{i} x_{n}^{i}, n=1, \ldots, N \\
& y_{p}^{j} \leq \sum_{i=1}^{m} \lambda_{i} y_{p}^{i}, p=1, \ldots, P \\
& \sum_{i=1}^{n} \lambda_{i}=1 \\
& \lambda_{i} \geq 0, i=1, \ldots, m
\end{aligned}
$$

In the 1990s, Chambers et al. $(1996,1998)$ proposed a new and more flexible measure involving production theory. They introduced the Directional Distance Function. It is the transposition in production theory of the Luenberger's Benefit Function (1992) which was developed in the consumer context.

The Directional Distance Function generalizes the traditional Shephard's Distance Function (1970) and plays a meaningful role in production theory. As its name indicates, the Directional Distance Function projects input and/or output vector from itself to the technology frontier in a pre-assigned direction. It determines a shortcut in one direction which permits to an observed DMU to reach the production frontier.

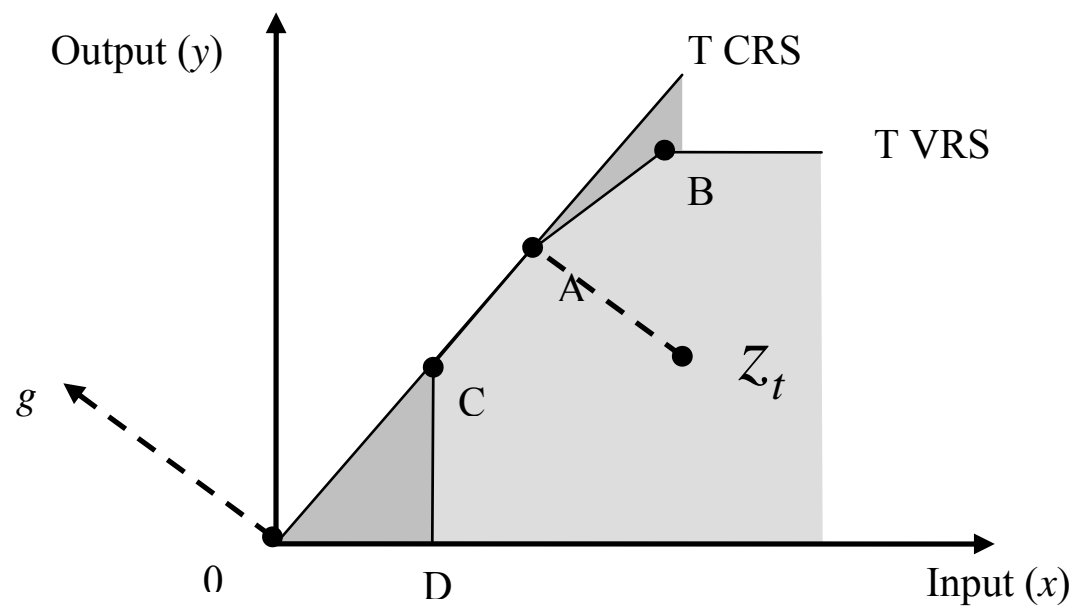

Figure 4 The Directional Distance Function 
In more economic terms, this function makes it possible to evaluate the scale of the economies and the possible improvements in production which can be achieved simultaneously by a DMU. Thus it is generally considered as an indicator of the performance of each observed entity.

To use this function, we have to find the technology set $T$. Throughout this paper, the technology satisfies the following conventional assumptions:

A1: $(0,0) \in T_{t},\left(0, y_{t}\right) \in T_{t} \Rightarrow y_{t}=0$ i.e., no free lunch;

A2: the set $A\left(x_{t}\right)=\left\{\left(u_{t}, y_{t}\right) \in T_{t} ; u_{t} \leq x_{t}\right\}$ of dominating observations is bounded $\forall x_{t} \in R_{+}^{N}$, i.e., infinite outputs are not allowed with a finite input vector;

A3: $T_{t}$ is closed;

A4: $\forall\left(x_{t}, y_{t}\right) \in T_{t},\left(x_{t},-y_{t}\right) \leq\left(u_{t},-v_{t}\right) \Rightarrow\left(u_{t}, v_{t}\right) \in T_{t}$, i.e., fewer outputs can always be produced with more inputs, and inversely (strong disposal of inputs and outputs);

A5: $T_{t}$ is convex.

The Directional Distance Function is defined as follows.

The function $D_{t}: R^{n+p} \times R^{n+p} \rightarrow R \cup\{-\infty\} \cup\{+\infty\}$ defined by:

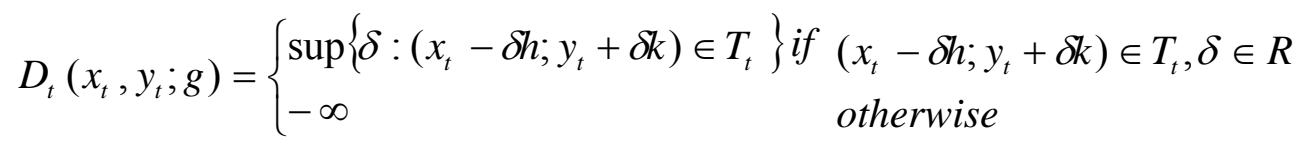

is called directional distance function in the direction of $g=(h, k)$.

In order to make more operational this approach, it is necessary to take an appropriate direction. We do this by considering the direction $g=(x, y)$.

The linear program that calculates the values of the Directional Distance Function is given by:

$D_{t}\left(x_{t}, y_{t}\right)=\max \delta_{t}$

subject to:

$$
\begin{aligned}
& x_{t}-\delta_{t} x_{t} \geq \sum_{n} \theta_{n} x_{t}^{n}, \quad n=1 \ldots N \\
& y_{t}+\delta_{t} y_{t} \leq \sum_{n}^{n} \theta_{n} y_{t}^{n}, \quad n=1 \ldots N \\
& \sum_{n=1}^{N} \theta_{n}=1 .
\end{aligned}
$$


Note that the constraint $\sum_{n=1}^{N} \theta_{n}=1$ corresponds to variable returns to scale. The choice of an assumption of returns to scale (constant versus variable) is important because it determines the technology of production representation. It can be stated that the adoption of variable returns to scale is appropriate as far as the tourism industry is concerned. Indeed, units are able to modify their scale in the short run with an assumption of constant return to scale. But constraints on finance or specific events such as terrorist attacks may cause a tourism organization to not be operating at optimal scale.

\section{Data and results}

Since the 1990s a number of studies have considered the measurement of efficiency in the tourism industry. As far as the hospitality sector is concerned, Morey and Ditman (1995), Johns et al. (1997), Anderson et al. (1999a), Anderson et al. (2000), Brown and Ragsdale (2002), Hwang and Chang (2003), Reynolds (2003), Barros and Alves (2004), Barros (2004), Chiang et al. (2004), Barros and Mascarenhas (2005), Barros (2005 and 2006) and finally Reynolds and Thompson (2007) use the DEA methodology for evaluating hotels efficiency. Thus, efficiency of hotels is a common research topic in the tourism context. From a policy perspective, these papers generally propose guidelines to overcome the identified inefficiency. A lot of these papers are empirically driven but sometimes, papers discuss hypothesis which say that there is a relation between an organizational or managerial aspect of the enterprise and its efficiency (for example Botti et al., 2009).

The analysis of travel agencies efficiency is a rarer issue as it is restricted to six papers: Bell and Morey (1995), Anderson et al. (1999b), Barros and Matias (2006), Barros and Dieke (2007), Köksal and Aksu (2007) and Barros et al. (2009).

Regarding our subject, i.e. destination performance, previous analysis are restricted to a small number of studies. We cite Bosetti et al. (2004) and Cracolici et al. (2006) who suggest DEA methodology but no Directional Distance Function frontier models to examine the performance of tourism regions. Thus, the main purpose of our paper is to contribute to the literature in this field by offering a somewhat new approach to assess tourism regions performance. As we said, this is a new and crucial issue. When we drafted this issue, according to the WTO, the number of tourists in the world was expected to stagnate or decline of up to $2 \%$ in 2009 compare to 2008 . With the USA, Europe was expected to be the most affected region as its source markets was already into recession. And all economists know that when the demand decreases, efficiency becomes a major issue, due to the ever more intense pressure of competition. 
When compared with other research fields, the bibliography of efficiency in the tourism industry is, as far as we are concerned, clearly brief for such an important aspect of the tourism industry. Yet, tourism is vital for many countries such as Thailand, Morocco or Fiji (Narayan, 2005). This is due to the large intake of money for domestic businesses and to the opportunity for employment in the service industries associated with tourism, i.e. transportation services such as taxis, accommodation such as hotels, and other hospitality industry services such as resorts. With the present paper, we seek to call the attention of management researchers to this neglected aspect of one of the fastest growing industries in the world (Bhattacharya and Narayan, 2005).

This paper is applied to the 22 French regions for the year 2006 (see Figure 5). France is actually divided into 26 regions, of which 21 are in continental metropolitan France, one is the island of Corsica, and four lie overseas. Regions do not have legislative autonomy, nor can they issue regulations. They levy their own distinct taxes (and receive a decreasing part of their budget from the national government which gives them a portion of the taxes it levies) and have considerable budgets, managed by a regional council.

In our study, we measure output by:

(i) arrivals

and inputs by

(ii) hotels

(iii) camping

(iv) parks,

(v) monuments,

(vi) beach kilometres and

(vii) Museums.

In Table 4 below, we present several characteristics of the regions analysed.

Table 4 Inputs and output (2006)

\begin{tabular}{|l|l|l|l|l|c|l|l|}
\multicolumn{1}{c|}{} & $\begin{array}{l}\text { (I) } \\
\text { Hotels }\end{array}$ & $\begin{array}{l}\text { (I) } \\
\text { Campsites }\end{array}$ & $\begin{array}{l}\text { (I) } \\
\text { Parks }\end{array}$ & $\begin{array}{l}\text { (I) } \\
\text { Monuments }\end{array}$ & $\begin{array}{l}\text { (I) } \\
\text { Beach }\end{array}$ & $\begin{array}{l}\text { (I) } \\
\text { Museums }\end{array}$ & $\begin{array}{l}\text { (O) } \\
\text { Arrivals }\end{array}$ \\
\hline $\begin{array}{l}\text { Mean } \\
\text { Standard } \\
\text { deviation }\end{array}$ & 813 & 370 & 16 & 4 & 14 & 58 & 4694607 \\
\hline Min & 648 & 265 & 12 & 3 & 19 & 32 & 6508557 \\
\hline Max & 246 & 99 & 2 & 0 & 0 & 10 & 867336 \\
\hline
\end{tabular}




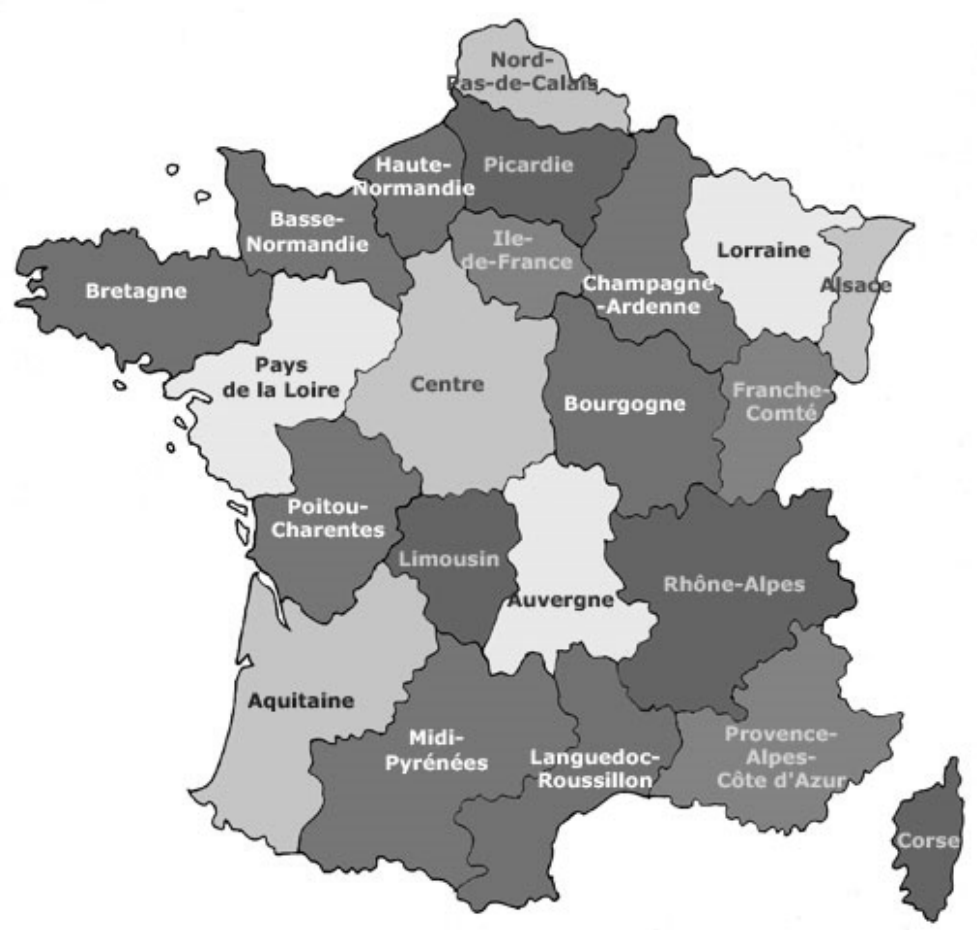

Figure 5 The French regions

The choice of the inputs stems from the fact that the number of tourists in a region depends, as we said in the second section of this paper, on tourism attractions (parks, monuments, beach kilometres and museums) and also on the accommodation capacity of the region.

The data are derived from official websites and from a statistical publication of the major tourism institution in France (ODIT France): kilometres,

- http://www.123plage.com/plages/index.php for the number of beach

- http://www.infoparks.com for the numbers of parks,

- http://museofile.culture.fr for the number of museum and monuments.

As we said in the previous section, the tourism industry is commonly characterized by variable returns to scale. With regards to the inputs and outputs we used here, we make also the assumption of VRS for the production technology. Moreover, it is impossible to talk about input reduction given our data (beaches can not be closed for example). Then, we measure the technical efficiency in an output orientation which corresponds from an economic viewpoint to an assumption of revenue maximization. In other words, we look at the possibility for a given region to increase its arrivals number without changing its inputs level. Concerning the linear programming we fix the following directional vector $g=(0, y)$. 
Table 5 Efficiency scores

\begin{tabular}{|l|c|}
\hline \multicolumn{1}{|c|}{ Regions } & Efficiency scores \\
\hline Picardie & 0 \\
\hline Alsace & 0 \\
\hline Nord-Pas-de-Calais & 0 \\
\hline Lorraine & 0 \\
\hline Limousin & 0 \\
\hline Ile-de-France & 0 \\
\hline Haute-Normandie & 0 \\
\hline Franche-Comté & 0 \\
\hline Champagne-Ardenne & 0 \\
\hline Corse & 0.004 \\
\hline Rhône-Alpes & 0.276 \\
\hline Bourgogne & 0.406 \\
\hline Poitou-Charentes & 0.414 \\
\hline Basse-Normandie & 0.421 \\
\hline Bretagne & 0.448 \\
\hline Centre & 0.459 \\
\hline Provence-Alpes-Côte-d'azur & 0.460 \\
\hline Pays de la Loire & 0.514 \\
\hline Midi-Pyrénées & 0.523 \\
\hline Aquitaine & 0.523 \\
\hline Languedoc-Roussillon & 0.549 \\
\hline Auvergne & \\
\hline
\end{tabular}

All the calculi are made using the Mathematica 5.0 software and the results are presented in Table 5. Ten of the 22 French regions are technically efficient; the output directional distance function of these areas experienced a nil result implying that there are on the production frontier. It can be stated that, except Ile-de-France, the 'famous' French tourism regions (Provence-Alpes-Côte d'azur and Languedoc-Roussillon) are not the most efficient.

As far as the interpretation of the results provided by the output directional distance functions, it can be stated the following for example: Languedoc-Roussillon is technically inefficient and it should increase its number of tourist arrivals by $52.3 \%$ without reduce their inputs level. As an inefficient region, Languedoc-Roussillon could 
use efficient peers to improve its performance, that is use these benchmarks in order to improve its tourism attraction and accommodation capacity management.

\section{Conclusion and discussion}

This paper proposed an analysis of the 22 French regions tourism performance. He presented the interest of this study and tried to expose the methodology as easiest as possible. When one talks about the efficiency of a firm, one usually means its success in producing as large as possible an output from a given set of inputs. Our paper adopted this direction and analyzed the French regions efficiency using an output-oriented projection model.

The general conclusion is that there is room for adjustment in 12 French regions in order to achieve best-practice procedures. These regions should adopt procedures that induce greater efficiency, in following the example of efficient peers identified in our benchmarking exercise.

However, more investigations are needed to confirm these first results. Obvious, a potential extension is the inclusion of data about labour in the tourism industry. Moreover, the performance scores could be connected to recent works on the concept of tourism attraction (Botti et al., 2008). So the paper will initiate a reflection on tourism attraction management in the French regions. Indeed, tourist arrivals to a destination depend on the way tourists consider it in terms of "attraction". Then, we can consider that the competitiveness of a region depends on the kind of the regions attractions. Along this line, the classification of Caccomo and Solonandrasana (2002) ("D-attractions" vs "E-attraction") could be useful. These concepts have ever been applied to the Languedoc-Roussillon region of France by Peypoch and Solonandrasana (2007). Their study confirmed that if an attraction is an "E-attraction" in the eyes of tourists, they will have a greater propensity to stay there longer as it is able to maintain their "satisfaction" at an acceptable level for a considerable period. Then a question arouses: empirically, is there a link between the kind of the region attractions and the efficiency score of the region? Moreover, this question could permit us to include in our reflexion the notions of "sustainable tourism" and "carrying capacity" (Peypoch et al., 2005).

The principal limitation of the paper is related to the data used. The homogeneity of the sample is questionable, since we compare regions with different dimensions and tourism characteristics. They may face different restrictions due to natural characteristics and therefore, might not be considered to be directly comparable. Moreover, due to these structural characteristics, there are different strategic options for these regions, and not all options are available to each region. However, we can always claim that the units are not comparable and then a ratio analysis could not equally be carried out. Moreover, the data set is short, thus the conclusions are limited, and especially in a VRS analysis where reducing the number 
of observations increases the likelihood that a given observation is judged relatively efficient (Banker, 1993).

\section{References}

1. Anderson, R. I., M. Fish, Y. Xia and F. Michello (1999a) Measuring efficiency in the hotel industry: A stochastic frontier approach. International Journal of Hospitality Management 18(1), pp. 45-57.

2. Anderson, R. I., D. Lewis and M. E. Parker (1999b) Another look at the efficiency of corporate travel management departments. Journal of Travel Research, 37(3), pp.267-272.

3. Anderson, R. I., R. Fok and J. Scott (2000) Hotel industry efficiency: An advanced linear programming examination. American Business Review, 18(1), pp.4048.

4. Barros, C. P. (2004) A stochastic cost frontier in the Portuguese hotel industry. Tourism Economics, 10(2): pp.177-192.

5. Barros, C. P. (2005) Measuring Efficiency in the Hotels: An Illustrative Example, Annals of Tourism Research, 32(2): 456-477.

6. Barros, C. P. (2006) Analyzing the rate of technical change in the Portuguese hotel industry. Tourism Economics, 12(3), pp. 325-346.

7. Barros, C. P. and P. Alves (2004) Productivity in tourism industry. International Advances in Economic Research, 10(3), pp. 215-225.

8. Barros, C. P. and M. J. Mascarenhas (2005) Technical and allocative efficiency in a chain of small hotels. International Journal of Hospitality Management, 24(3), pp. 415-436.

9. Barros, C. P. and A. Matias (2006) Assessing the efficiency of travel agencies with a stochastic cost frontier: A Portuguese case study. International Journal of Tourism Research, 8(5), pp. 367-379.

10. Barros, C. P. and P. U. C. Dieke (2007) Analyzing the total productivity change in travel agencies. Tourism Analysis, 12(1-2), pp. 27-37.

11. Barros, C. P., L. Botti and N. Peypoch (2009) A framework to analyse productivity changes: Theoretical aspects and applications to the Portuguese travel agencies sector. Tourism Analysis, forthcoming.

12. Barros, C. P., L. Botti, N. Peypoch and B. Solonandrasana (2009) Managerial efficiency and hospitality industry: The Portuguese case. Applied Economics, forthcoming.

13. Banker, R. D. (1993) Maximum likelihood, consistency and data envelopment analysis. Management Science, 39(10), pp. 1265-1273.

14. Banker, R. D., A. Charnes and W. Cooper (1984) Some models for estimating technical and scale efficiency in data envelopment analysis. Management Science, 30(9), pp. 1078-1092. 
15. Bhattacharya, M. and P. K. Narayan (2005) Testing for the random walk hypothesis in the case of visitor arrivals: Evidence from Indian tourism. Applied Economics, 37(13), pp. 1485-1490.

16. Bosetti, V., M. Cassinelli and A. Lanza (2006) Benchmarking in tourism destination, keeping in mind the sustainable paradigm. Nota di Lavoro, Fondazione Eni Enrico Mattei.

17. Botti, L., N. Peypoch and B. Solonandrasana (2008) Time and tourism attraction. Tourism Management, 29(3), pp. 594-596.

18. Botti, L., W. Briec and G. Cliquet (2009) Plural forms versus franchise and company-owned systems: A DEA approach of hotel chain performance. OMEGA: The International Journal of Management Science, 37(3), pp. 566-578

19. Bell, R. A. and R. C. Morey (1995) Increasing the efficiency of corporate travel management through macro-benchmarking. Journal of Travel Research, 33(3), pp. 11-20.

20. Briec, W. (1997) A graph-type extension of Farrell technical efficiency measure. Journal of Productivity Analysis, 8(1), pp. 95-110.

21. Brown, J. R. and C. T. Ragsdale (2002) The competitive market efficiency of hotel brands: An application of data envelopment analysis. Journal of Hospitality and Tourism Research, 26(4), pp. 332-360.

22. Caccomo, J. L. and B. Solonandrasana (2002) Réflexions autour du concept d'attraction touristique: Analyse et taxonomie, Revue de Recherche en Tourisme UQAM (Canada), 21(3), pp. 68-71.

23. Chambers, R. G., Y. Chung and R. Färe (1996) Benefit and distance functions. Journal of Economic Theory, 70(2), pp. 407-419.

24. Chambers, R. G., Y. Chung and R. Färe (1998) Profit, directional distance functions, and Nerlovian efficiency. Journal of Optimization Theory and Applications, 98(2), pp. 351-364.

25. Charnes, A., W. W. Cooper and E. Rhodes (1978) Measuring the efficiency of decision making units. European Journal of Operational Research, 2(6), pp. 429444.

26. Chiang, W. E., M. H. Tsai and L. S. M. Wang (2004) A DEA evaluation of Taipei hotels. Annals of Tourism Research, 31(3), pp. 712-715.

27. Chu, F. L. (1998) Forecasting tourism: A combined approach. Tourism Management, 19(6), pp. 515-520.

28. Coelli, T. J., D. S. P. Rao , C. O’Donnell and G. E. Battese, (2005) An introduction to efficiency and productivity analysis. Springer

29. Cracolici, M. F., P. Nijkamp and P. Rietveld (2006) Assessment of tourist competitiveness by analysing destination efficiency. Tinbergen Institute Discussion Paper №06-097/3, http://ideas.repec.org/p/dgr/uvatin/20060097.html

30. Debreu, G. (1951) The coefficient of resources utilization. Econometrica, 19(3), pp. 273-292. 
31. Dwyer, L., P. Forsyth, and P. Rao (2000) The price competitiveness of travel and tourism: A comparison of 19 destinations. Tourism Management, 21(1), pp. 9-22.

32. Farrell, M. (1957) The measurement of productive efficiency. Journal of the Royal Statistical Society, Series A: General, 120(3), pp. 253-281.

33. Crouch, G. I. and J. R. Ritchie, (1999) Tourism competitiveness and societal prosperity. Journal of Business Research, 44(3), pp. 137-152.

34. Crouch, G. (2006) Destination competitiveness: Insight attributes importance. Paper presented at the International conference of Trends, Impacts and Policies on Tourism development, Crete, $15^{\text {th }}-18^{\text {th }}$ June 2006.

35. Hwang, S. N. and T. Y. Chang (2003) Using data envelopment analysis to measure hotel managerial efficiency change in Taiwan. Tourism Management, 24(4), pp. 357-369.

36. Johns, N., B. Howcroft and L. Drake (1997) The use of data envelopment analysis to monitor hotel productivity. Progress in Tourism and Hospitality Research, 3(2), pp.119-127.

37. Köksal, C. D. and A. A. Aksu (2007) Efficiency evaluation of A-group travel agencies with Data Envelopment Analysis (DEA): A case study in the Antalya region, Turkey. Tourism Management, 28(3), pp. 830-834.

38. Lovell, C. A. K. and P. Schmidt (1988) A comparison of alternative approaches to the measurement of productive efficiency. In: Dogramaci, A. and R. Färe (eds.) Applications of modern production theory: Efficiency and productivity, Kluwer, pp. 3-32.

39. Lovell, C. A. K. (1993) Production frontiers and productive efficiency. In: Fried, H., C. A. K. Lovell, and S. Schmidt (eds.) The measurement of productive efficiency: Techniques and applications, Oxford University Press, pp. 3-67.

40. Luenberger, D. G. (1992) Benefit function and duality. Journal of Mathematical Economics, 21(5), pp. 461-481.

41. Morey, R. C. and D. A. Dittman (1995) Evaluating a hotel GM's performance: A case study in benchmarking. Cornell Hotel Restaurant and Administration Quarterly, 36(5), pp.30-35.

42. Narayan, P. K. (2005) The structure of tourist expenditure in Fiji: Evidence from unit root structural break tests. Applied Economics, 37(10), pp. 1157-1161.

43. Nooreha, H., A. Mokhtar and K. Suresh (2000) Evaluating public sector efficiency with data envelopment analysis: A case study in road transport department, Selangor, Malaysia. Total Quality Management, 11(4), pp. 830-836.

44. Peyroutet, C. (1998) Le Tourisme en France. Paris: Nathan.

45. Peypoch, N. and B. Solonandrasana (2007) On e-attraction tourism destination: Extension and application. In A. Matias, P. Neto, and Nijkamp, P. (eds.) Advances in Modern Tourism Research. Springer-Verlag, pp. 293-306. 
46. Peypoch, N., E. Robinot and B. Solonandrasana (2006) Which sustainable development perspectives for an e-attraction destination: An overview of the economic impacts. Tourism and Hospitality Planning and Development, 2(3), pp. 207-212.

47. Porter, M. (1990) The Competitive Advantage of Nations. London: The Macmillan Press.

48. Poon, A. (1993) Tourism, Technology and Competitive Strategies. Wallingford: CABI Publishing.

49. Randriamboarison, R. (2001) La demande touristique: Résumé des travaux empiriques. Unpublished paper, France: University of Perpignan.

50. Ray, S. C. (2004) Data envelopment analysis: Theory and techniques for economics and operations research. Cambridge University Press.

51. Reynolds, D. (2003) Hospitality-productivity assessment using data envelopment analysis. Cornell Hotel and Restaurant Administration Quarterly, 44(2), pp.130-137.

52. Reynolds, D. and F. M. Thompson (2007) Multi-unit restaurant productivity: Assessment using three-phase data envelopment analysis. International Journal of Hospitality Management, 26(1), pp. 20-32.

53. Richie, J. R. B. and G. Crouch (2003) The competitive destination: A sustainable tourism perspective. Wallingford: CABI Publishing.

54. Shephard, R. W. (1970) Theory of cost and production functions. Princeton: Princeton University Press.

55. Tavares, G. (2002) A bibliography of data envelopment analysis (19782001). RUTCOR Research Report.

56. Tulkens, H. (1993) On FDH efficiency analysis: Some methodological issues and applications to retail banking, courts, and urban transit. The Journal of Productivity Analysis, 4(1-2), pp. 183-210.

57. Vanhove, N. (2005) The economics of tourism destinations. Elsevier.

RECEIVED: 14.11 .2008

ACCEPTED: 20.04.2009 